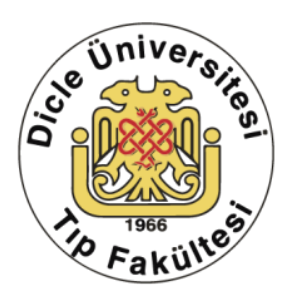

\title{
Ceza İnfaz Kurumlarının Yönetim, Dış Koruma, Hükümlü ve Tutukluların Sevk ve Nakilleri ile Sağlık Hizmetlerinin Yürütülmesi Hakkındaki Protokolün Bir Olgu Sunumu Üzerinden Adli Tıbbi Değerlendirilmesi
}

\author{
Yaşar Tıraşçı1 ${ }^{1}$, Cem Uysal ${ }^{2}$, Aydın Altınal ${ }^{3}$, Mustafa Akın ${ }^{4}$, Ubeydullah Durmaz \\ 1 Dicle Üniversitesi Tıp Fakültesi Adli Tıp AD. Diyarbakır, Türkiye ORCID: 0000-0002-7164-037 \\ 2 Dicle Üniversitesi Tıp Fakültesi Adli Tıp AD. Diyarbakır, Türkiye ORCID: 0000-0002-7373-972 \\ 3 Dicle Üniversitesi Tıp Fakültesi Adli Tıp AD. Diyarbakır, Türkiye ORCID: 0000-0001-6122-628X \\ 4Dicle Üniversitesi Tıp Fakültesi Adli Tıp AD. Diyarbakır, Türkiye ORCID: 0000-0002-9041-157 \\ 5 Dicle Üniversitesi Tıp Fakültesi Adli Tıp AD. Diyarbakır, Türkiye ORCID: 0000-0001-5361-3888
}

Geliş: 24.04.2017, Revizyon: 22.09.2017, Kabul Tarihi: 25.09.2017

\section{Özet}

Hekimlik mesleğinin; hastalar arasında sosyal durum, dini inanç, siyasi görüș, milliyet, cinsiyet, yaș ve sosyoekonomik durum farklılıkları gözetmeksizin icra edilmesi gerekmektedir. Ancak tutuklu/hükümlü muayenelerinde Ceza İnfaz Kurumlarının Yönetim, Dış Koruma, Hükümlü ve Tutukluların Sevk ve Nakilleri ile Sağlı Hizmetlerinin Yürütülmesi Hakkındaki Protokolün (3’lü Protokol) yorumlanması ve uygulanmasına bağlı olarak çeşitli sorunlarla karşılaşılmaktadır. Bu çalışmamızda kolluk kuvvetleri eşliğinde cezaevinden Dicle Üniversitesi Tıp Fakültesi Adli Tıp AD’na muayeneye getirilen bir şahsın muayenesi esnasında kolluk kuvvetleri ile hekimler arasında 3'lü protokol nedeniyle yaşanan bir olay ele alınmış olup çözüm önerilerinde bulunulmuştur.

Anahtar kelimeler: İstanbul Protokolü, 3’lü Protokol, Tutuklu/Hükümlü Muayenesi 


\title{
Forensic Medical Assessment of the Protocol on the Management of Prisons and Detention Houses, External Protection, Dispatch and Transport and Implementation of Health Services of the Convicts and Prisons from a Case Report
}

\begin{abstract}
In medical profession, depending on its own ethical rules, does not discriminate patients among social status, religious beliefs, political views, nationality, sex, age, social position and economic situation. But there are many contradictions depending on the interpretation and application of The Protocol on the Management of Prisons and Detention Houses, External Protection, Dispatch and Transport and Implementation of Health Services of the Convicts and Prisons (triple protocol). In this study, we discuss an unpleasant case due to implication of the triple protocol between the law enforcement officers and the physicians during the examination of a person brought to Dicle University Medical Faculty Department of Forensic Medicine from jail and we make suggestions to overcome the some troubles.
\end{abstract}

Keywords: Istanbul Protocol, Triple Protocol, Prisoner/Convict Examination

\section{GİRiş}

Hekimlik mesleğini uygularken insan onurunu ve haklarını gözetmek hekimin öncelikli görevlerindendir. Hekimlerin mesleklerini icra ederken uyması gereken evrensel tıbbi etik ilkeleri yararlılık, adalet, zarar vermeme ve özerkliktir. Hekim hastaları arasındaki sosyal durum, dini inanç, siyasi görüş, milliyet, cinsiyet, yaş, toplumsal konum ve ekonomik durum gibi farklılıkları gözetmeksizin mesleğini yerine getirmekle yükümlüdür. Tutuklu ve hükümlülerin muayeneleri normal hastalardan hiç fark oluşturmayacak şekilde kişilik haklarına saygılı, hekimlik sanatını uygulamaya elverişli koşullarda ve onların gizlilik hakları korunarak yapılmalıdır ${ }^{1}$.

Ceza İnfaz Kurumlarının Yönetim, Dış Koruma, Hükümlü ve Tutukluların Sevk ve Nakilleri ile Sağlık Hizmetlerinin Yürütülmesi Hakkındaki Protokol (3'lü Protokol) 2003 yllında çıkartılmış ancak 19.08.2011 yılında revize edilmiş en son halini 26.01.2017 tarihinde almıştır. $\mathrm{Bu}$ protokolün muayenelerde güvenliğin ve hasta mahremiyetinin sağlanması ile ilgili olan 38. Maddesi'nde "Hükümlü ve tutuklularm hastanelerde muayeneleri, firara karşı engellerin bulunduğu muhafazalı odalarda yapılır. Jandarma muayene esnasında oda dişında bulunur ve gerekli güvenlik tedbirlerini alır. Doktorun yazılı olarak talep etmesi halinde jandarma muayene odasında bulunur. Hastanelerde tutuklu ve hükümlüler için muhafazalı muayene odaları yapılıncaya kadar jandarma muayene odası içinde bulunur ve doktorla hasta arasında geçecek konuşmaları duymayacak uzaklıkta koruma tedbirini alır" denilmektedir². Ayrıca Sağlık Bakanlığı Tedavi Hizmetleri Genel Müdürlüğü'nün 05.10.2011 tarih ve 40696 sayılı protokolü de 3'lü Protokol temel alarak hazırlanmış ve tüm hastanelere dağıtılmıştır ${ }^{3}$. Ancak muhafazalı muayene odası bulunmayan ve doktor-hasta arasında geçecek konuşmaların duyulmayacak kadar genişlikte muayene odası bulunmayan yerlerde hükümlü muayenelerinde çeșitli aksakllklarla karşlaşılmaktadır.

Ülkemiz İstanbul Protokolü'nü 1999 yılında imzalamış olup 2000 yılından itibaren geçerli olmuştur. Birleşmiş Milletler İnsan Hakları Komisyonu İstanbul Protokolü ilkelerini 20 Nisan 2000'de benimsemiştir. İstanbul Protokolü'nün, tüm gözaltı giriş-çıkış, yer değiștirme amacıyla yapılan sağlık kontrolü muayenelerinde, tutuklu/hükümlü muayeneleri ve bireysel başvurularda, insan hakları ihlallerinin araştırılması amacıyla hukukçular ve hekimler tarafından uygulanması gerekmektedir ${ }^{4,5}$.

Anayasamızın 90. Maddesi "Türkiye Cumhuriyeti adına yabancı devletlerle ve 
milletlerarası kuruluşlarla yapılacak antlaşmaların onaylanması, Türkiye Büyük Millet Meclisinin onaylamayı bir kanunla uygun bulmasına bağlıdır. Usulüne göre yürürlüğe konulmuş milletlerarası antlaşmalar kanun hükmündedir. Usulüne göre yürürlüğe konulmuş temel hak ve özgürlüklere ilişkin milletlerarası antlaşmalarla kanunların aynı konuda farklı hükümler içermesi nedeniyle çıkabilecek uyuşmazlıklarda milletlerarası antlaşma hükümleri esas alınır" denilmektedir6.

Çalışmamızın temelini tutuklu/hükümlü muayenesi sirasında kolluk kuvvetlerinin gerekçe olarak kullandıkları Ceza İnfaz Kurumlarının Yönetim, Dış Koruma, Hükümlü ve Tutukluların Sevk ve Nakilleri ile Sağlık Hizmetlerinin Yürütülmesi Hakkındaki Protokolü ile hekimlerin muayene sirasında uygulamak zorunda oldukları ilkelerinin çakıştığı durumların irdelenmesi oluşturmaktadır.

\section{OLGU}

16 yaşında cezaevinde tutuklu olarak bulunan olgu tarafımıza 2 yll önce işlediği iddia edilen cinsel istismar olayı nedeni ile jandarma kolluk kuvvetleri tarafından elleri kelepçeli olarak suçun hukuki anlam ve sonucunu anlayıp anlayamadığı ve davranışlarını yönlendirme yeteneğinin yeterince gelişip gelişmediğinin tespiti için anabilim dalımıza getirildi. Şahıs muayeneye alınmadan önce kolluk kuvvetlerinden failin kelepçelerinin açılması istenildi. Kolluk kuvvetlerinden bir astsubayın muayene yapılacak odaya gelerek gözlem yapmasının ardından odada demir parmaklıklar bulunmaması gerekçe gösterilerek muayene sirasında muayene odasından dışarı çıkmak istememesi üzerine kendisine bu șekilde muayene yapılamayacağı belirtildi. Adli Tip AD muayene odasının hastanenin 4. katında olduğu belirtilerek, muayene odasının küçük olması ve yapılacak görüşmeyi duyabileceği için kolluk kuvvetlerinin kapının dışında beklemesi gerektiği ve failin camlı olan kısımda değil kapıya yakın kısımda oturtulacağı belirtildi.

Kolluk kuvvetlerinin itiraz etmesi üzerine cinsel muayene odasında failin muayenesinin yapılacağı belirtilerek odanın kolluk kuvvetleri tarafından gözlemlenmesi sağlandı. Cinsel muayene odasının tek bir giriş ve çıkışının bulunması ve 3 tarafının duvarlarla çevrili olduğu halde kolluk kuvvetleri kulaklarına pamuk tıkayarak sırtları dönük olacak şekilde odada bulunmaları gerektiği yönünde istemlerinin olması üzerine böyle bir durumun söz konusu olamayacağı belirtildi.

Astsubay tarafından komutanı aranarak durum bildirildi. Komutanı tarafından böyle bir odada muayene yapılabileceği ancak doktorların başına herhangi bir istenmeyen durum gelirse sorumluluk kabul edilmeyeceği bu nedenden dolayı da tutanak tutulması gerektiği bildirildi. Daha sonra kolluk kuvvetleri tarafindan savcl aranarak durum hakkında bilgi verildi ve savcının talimatı üzerine böyle bir tutanak tutulmasına gerek olmadığı belirtildi. Muayene öncesinde, sirasinda ve sonrasinda kolluk kuvvetleri ile herhangi bir tartışmaya yer verecek durum yaşanmadı. Muayene bittikten sonra kolluk kuvvetleri tarafından birkaç gün önce bir tutuklunun kaçtığ görüşme sona erdirildi.

\section{TARTIŞMA}

3'lü Protokol gereğince hastanelerde tutuklu ve hükümlüler için muhafazalı muayene odaları yapılıncaya kadar jandarmanın muayene odası içinde bulunması ve doktorla hasta arasında geçecek konuşmaları duymayacak uzaklıkta koruma tedbirini alması öngörülmektedir ${ }^{2}$. Bu protokol neticesinde, özellikle jandarma kuvvetleri ile hekimler arasinda hasta mahremiyeti ile ilgili problemler yaşanmaktadır. Duyma mesafesinin ne kadar olduğu tam belli olmamakla beraber bu mesafe kişisel özelliklere bağlı olarak sübjektif farklılıklar gösterebilmektedir. 
İstanbul Protokolünün 124. Maddesinde; "Her alıkonulan, mahremiyetine saygı gösterilen bir ortamda muayene edilmelidir. Polis ya da diğer kolluk güçleri hiçbir zaman muayene odasında bulunmamalıdır. $\mathrm{Bu}$ usule ilişkin önlemden sadece muayeneyi yapan hekim, eğer alıkonulanın sağlık personeline karşı ciddi bir güvenlik riski oluşturduğu yönünde ikna edici bir delili olduğunu düşünüyorsa vazgeçilebilir. Böyle bir durumda, muayene eden hekimin talebi üzerine, muayene esnasinda polis ya da diğer kolluk kuvvetleri değil, sağlık kurumunun güvenlik personeli hazır bulunmalıdır. $\mathrm{Bu}$ koşulda da, güvenlik personeli hastaya göre işitme mesafesinin dışında, yani yalnızca görüş mesafesinin içinde olmalıdır." denilmektedir7. Ayrıca Biyoetik Sözleşmesi'nin 10. Maddesinde; "Herkes, kendi sağlığıyla ilgili bilgiler bakımından, özel yaşamına saygı gösterilmesini isteme hakkına sahiptir" denilmekte ve 25 . Maddesinde ise;" Taraflar, bu Sözleşme' de yer alan hükümlerin ihlal edilmesi halinde uygulanacak uygun yaptırımları sağlayacaklardır" denilmektedir ${ }^{8}$. İstanbul Protokolü ve Biyoetik sözleşmesi Anayasamızın 90. Maddesi gereğince kanun hükmündedir6. Buradan da anlaşılabileceği gibi aslında 3'lü Protokol ile İstanbul Protokolü arasında çelişki bulunmaktadır.

İlaveten 1998 yılında yürürlüğe giren ve en son 20.10.2016 tarihinde güncellenen Hasta Hakları Yönetmeliği'nin 21. Maddesinde; "Hastanın, mahremiyetine saygı gösterilmesi esastır. Hasta mahremiyetinin korunmasını açıkça talep de edebilir. Mahremiyete saygı gösterilmesi ve bunu istemek hakkı; hastanın, sağllk durumu ile ilgili tıbbi değerlendirmelerin gizlilik içerisinde yürütülmesini, muayenenin, teşhisin, tedavinin ve hasta ile doğrudan teması gerektiren diğer işlemlerin makul bir gizlilik ortamında gerçekleștirilmesini, tedavisi ile doğrudan ilgisi olmayan kimselerin, tıbbi müdahale sırasında bulunmamasını" kapsar9.

Türk Tabipler Birliği'nin (TTB) Aralık 1994'te Tutuklu ve Hükümlülere Yönelik Sağlık
Hizmetleri ile ilgili bildirgesinde şu noktalara dikkat çekilmiştir: "Muayeneler sırasında hastaların kelepçeleri açtırılmalı, klinik özgürlük koşullarına ve hasta haklarına uygun tam bir ortam sağlanmalıdır. Bunun için muayene ortamlarında hasta ve sağllk personeli dışında kimse bulunmamalıdır. Bu hasta ve hekimin hakkı ve hekimin görevidir. Mahkûmların hasta yataklarına zincirlenmesi, kelepçelenmesi veya birtakım tıbbi girişimlerin bunların eşliğinde gerçekleştirilmesi mutlaka engellenmelidir. Hasta odalarında jandarma ve gardiyan bulundurulmamalıdır. Hastane ve eklentilerinde yetki ve sorumluluk hekimindir. Hekimler bu yetkilerini hekim dışı kişilere devredemez. Muayenenin yapıldığı ve mahkûm yatışının olduğu servislerde gerekli sayıda sağlık personeli bulundurulmalıdır. Tüm hekimler bu tutumu almakla yükümlüdür, bu tutumlardan dolayı zarar gören hekimler bu durumu acilen en yakın tabip odası ve TTB'ne bildirmelidirler" denilmektedir".

Adli olgu muayenelerinin farkı temel olarak tedavi etme prensibine dayanmaz. Tedavi genellikle sekonder bir amaçtır. Adli tıp muayenelerinde genellikle ya bir mağdur ya bir sanık ya da bir tanık vardır. Bu tip muayenelerde hasta sırrı ve mülkiyeti korunarak tıbbi deontoloji kurallarına en üst düzeyde dikkatlice uyularak hareket edilmesi gerekmektedir ${ }^{10}$. Hastane idaresinden sorumlu olan yöneticilerin bu tip muhafazalı muayene odalarını hazırlaması ya da hazırlamak isteyenlere ön ayak olması gerekmektedir. Bu çelişkili Protokolün uygulanması gerekliymiş gibi gözükse de,daha sonra hem cezai hem de tazmini olarak geri dönüşü ağır olabilecek ciddi hukuksal problemlere neden olabilecektir.

$\mathrm{Bu}$ konuda önerilerimiz; eğer koşullar el veriyorsa Adli Tıp işlemlerinin aynı birim içerisinde verilmesi, mümkünse zemine yakın yerlerde tercihen zemin katlarda parmaklıklı muayene odalarının yapılması, kolluk kuvvetlerinin muayene süreci içerisinde sadece suçlu kişi kaçabilme ihtimaline karşın dış 
güvenliği sağlaması, ister mağdur ister suçlu olsun mümkünse ilk getirilişi esnasında tüm işlemlerinin bitirilmesi, muhafazalı muayene odalarının dışarı ses geçirmez nitelikte olması, hastalardan izin almak koşuluyla gerekli ses ve görüntü kayıtlarının alınarak çok gizli bir ortamda güvenlik protokollerince saklanması ve şahsın başka birimlerce tekrarlı çağrılmasının önüne geçilmesidir Ayrıca bu şahısların hastane poliklinik girişleri esnasında genellikle kolluk kuvvetleri eşlik etmektedir. $\mathrm{Bu}$ işleyiş etik ilkeler içerisinde hoş bir görüntü olmayıp kişiyi teşhir etme anlamında da değerlendirilebileceğinden sivil klyafetli görevlilerin refakat etmesinin daha uygun olacaktır.

Sonuç olarak; 3'lü Protokol gereğince işlerini yapmaya çalışan kolluk kuvvetleri aldıkları emirler doğrultusunda hareket etmekte ancak bu protokole uymadıklarında haklarında soruşturma açlan devlet memurlarıdır. Hekimler de aynı mevzuat kapsamında görevlerini ifa etme gayreti içerisindedirler. Nasıl ki kolluk kuvvetleri muayene odası içerisinde kalmalarını 3'lü Protokole bağlıyorlarsa hekimlerinde bu protokol kapsamında adli ve idari sorumluluğu olduğu unutmamalıdırlar. Ülkemiz açısından uluslararası hukuk çevrelerinde sıkıntı oluşturma potansiyeli olan 3'lü Protokoldeki çelişkilerin düzeltilmesi için, kanun yapıcı ve uygulayıcılar tarafından tekrar gözden geçirilmesinin uygun olacağı kanaatindeyiz.

Çıkar Çatışması Beyanı: Yazarlar çıkar çatışması olmadığını bildirmişlerdir.

Finansal Destek: Bu çalışma her hangi bir fon tarafından desteklenmemiştir.

Declaration of Conflicting Interests: The authors declare that they have no conflict of interest.

Financial Disclosure: No financial support was received.

\section{KAYNAKLAR}

1. (TTB) TTB. Türk Tabipleri Birliği (TTB) Hekimlik Meslek Etiği Kuralları. Türk KardiyolDern Arş - Arch Turk Soc Cardiol. 2009;37:46-50.

2. Adalet Bakanlığı. Ceza İnfaz Kurumlarının Yönetim, Dış Koruma, Hükümlü Ve Tutukluların Sevk Ve Nakilleri İle Sağlık Hizmetlerinin Yürütülmesi Hakkında Protokol, 2017. Available at: www.cte.adalet.gov.tr/ menudekiler/mevzuat /protokol/P12.doc. Accessed 19. 08. 2011.

3. Sağlık Bakanlığı. Tutuklu ve Hükümlülerin Hastanelerde Muayene ve Tedavileri. 2011. Available at:http://www.saglik.gov.tr/TR/dosya/1-73510/h/ protokol.pdf. Accessed 05. 10. 2011.

4. Can İÖ. İstanbul Protokolü. 2010. Available at: http://www.izmirtabip.org.tr/L/TR/mid/396/hcid/5/ hid/168/Istanbul_Protokolu.htm. Accessed 22. 12.2010 .

5. Iacopino V, Ozkalipci O, Schlar C. TheIstanbul Protocol: international Standard sfor the effectiveinvestigation and documentation of tortureandilltreatment. Lancet. 1999;354:1117.

6. Yalvaç G. TC Anayasası. In: Yalvaç G, ed. TC Anayasası, TCK, CMK, CGTIK. Ankara: Adalet Yayınevi; 2010:38-39.

7. Türk Tabipleri Birliği. İstanbul Protokolü, İşkence ve Diğer Zalimane, İnsanlık Dışı, Aşağılayıcı Muamele veya Cezaların Etkili Biçimde Soruşturulması ve Belgelendirilmesi İçin Kılavuz. İstanbul: Başak Matbaacılık Ltd. Şti; 2009.

8. Adalet Bakanlığı. Biyoloji ve Tıbbın Uygulanması Bakımından İnsan Hakları ve İnsan Haysiyetinin Korunması Sözleşmesi: İnsan Hakları ve Biyotıp Sözleşmesinin Onaylanmasının Uygun Bulunduğuna Dair Kanun. 2003. Available at: https://www.tbmm.gov.tr/kanunlar/k5013.html. Accessed 03. 12., 2003.

9. Sağlık Bakanlığı. Hasta Hakları Yönetmeliği. 1998, Güncellenme Tarìhİ: 20.10.2016. Available at: http://www.mevzuat.gov.tr/Metin.Aspx?MevzuatKod= 7.5.4847\&MevzuatIliski=0\&sourceXmlSearch=hasta\%2 0haklar\%C4\%B1. Accessed 01. 08.,1998.

10. Korkut, B. (2016) Türkiye' de Hasta Mahpus Olmak. TCPS Kitaplığı. 